\title{
Formación universitaria e inserción laboral. Titulados españoles con discapacidad y competencias profesionalizadoras ${ }^{1}$
}

\section{Higher Education and labour integration. Spanish graduates with disabilities and professional competence}

\section{Resumen}

La finalidad de este estudio ha sido explorar los puntos fuertes y débiles detectados por los titulados universitarios españoles con discapacidad en su proceso de educación universitaria e inserción en el mercado laboral ordinario, así como la experiencia y la opinión de las empresas en relación a este tema. La metodología utilizada ha sido cuantitativacualitativa y descriptiva. La muestra participante se configuró a partir de 687 titulados universitarios españoles con discapacidad, 77 estudiantes universitarios con discapacidad, I9 Servicios universitarios de Apoyo y I 6 empresas. Los resultados y las conclusiones nos permiten afirmar que: los titulados universitarios con discapacidad, generalmente, no reciben en la universidad los apoyos adecuados para poder desarrollar, suficientemente, las competencias profesionales; las prácticas profesionalizadoras son una oportunidad para la inserción laboral de los titulados con discapacidad; la discapacidad prevalece por encima de la calidad del currículum vitae en el momento del acceso al mercado laboral ordinario.

\section{Palabras clave \\ Educación superior, prácticas en la educación universitaria, competencias profesionalizadoras, titulados universitarios con discapacidad, inserción laboral, servicios universitarios de apoyo.}

\begin{abstract}
The aim of this study was to explore the strengths and weaknesses detected by Spanish university graduates with a disability in the process of university education and integration into the mainstream labour market, as well as the experience and opinion of companies concerning this issue. The method used was quantitativequalitative and descriptive. The participating sample consisted of 687 Spanish university graduates with a disability, 77 university students with a disability I9 University Support Services, and I 6 companies. Results and conclusions allow us to confirm that: (I) university graduates with a disability, in general, are not provided with appropriate support at university to develop their professional competence sufficiently; (2) professionalizing practices are an opportunity for the employment of graduates with a disability; (3) disability prevails over the quality of the person's curriculum vitae when entering the mainstream labour market.
\end{abstract}

\section{Keys words}

Higher education; higher education practices; professional competences; university graduates with a disability; employability; university support services

\author{
Mariona Dalmau Montalà \\ <marionadm@blanquerna.url.edu> \\ Facultad de Psicología, Ciencias de la \\ Eduación y del Deporte Blanquerna. \\ Universidad Ramon Llull
}

\section{Montserrat Llinares Fité}

Facultad de Psicología, Ciencias de la Eduación y del Deporte Blanquerna. Universidad Ramon Llull

\section{Ingrid Sala Bars}

Facultad de Psicología, Ciencias de la Eduación y del Deporte Blanquerna. Universidad Ramon Llull

I. El contenido de este artículo es la síntesis del informe Integración laboral de los universitarios españoles con discapacidad. Detección de las fortalezas y debilidades en el momento del acceso al mercado laboral español. Percepción de los universitarios y percepción de las empresas, elaborado por las mismas autoras. Este informe es el resultado de un trabajo financiado en su totalidad por Fundación Universia. Puede ser consultado íntegramente en la web de dicha Fundación: <http://www.fundacionuniversia.net/ programas/informacion/informes/detalleProgramas-I 570. html>.

Para citar:

Dalmau Montalà, M. et al. (2013):

"Formación universitaria e inserción laboral. Titulados españoles con discapacidad y competencias profesionalizadoras". Revista Española de Discapacidad, I (2): 95-I I 8.

<http://dx.doi.org/I0.5 569/23405 I04.01.02.06>

Fecha de recepción: 24-OI-20I3 Fecha de aceptación: 4-I I-20I3 


\section{Antecedentes y fundamentación teórica}

Para profundizar sobre la inserción laboral de los titulados universitarios con discapacidad y detectar aquellos aspectos que pueden ayudarnos en el abordaje del estudio se ha considerado oportuno hacer una revisión de la legislación y la literatura existente sobre el tema. Antes de la entrada en España de la democracia nos encontramos con poca legislación que regule los temas relacionados con las personas con discapacidad.

Es en la Constitución Española (I978), donde encontramos los fundamentos sobre el reconocimiento de los deberes y de los derechos de todos los españoles: "Todos los españoles tienen el deber de trabajar y el derecho al trabajo, a la libre elección de profesión u oficio, a la promoción a través del trabajo y a una remuneración suficiente para satisfacer sus necesidades y las de su familia, sin que en ningún caso pueda hacerse discriminación por razón de sexo" (Capítulo II, Sección 2, Artículo 35 , Puntor).

Posteriormente, en la Ley de Integración Social del Minusválido (Ley I3/I982, LISMI) se reconoce oficialmente, por primera vez en el Estado Español, la integración de las personas con discapacidad en el sistema ordinario de trabajo: "Será finalidad primordial de la política de empleo de trabajadores minusválidos su integración en el sistema ordinario de trabajo o, en su defecto, su incorporación al sistema productivo mediante la fórmula especial de trabajo protegido que se menciona en el artículo 4I." (Título séptimo de la integración laboral, artículo 47). La implementación de la LISMI genera unos derechos sociales, pero también prestaciones económicas y beneficios fiscales que ayudan a mejorar la situación de desventaja social derivada de la minusvalía. Con el objetivo de configurar una acción solidaria que tienda hacia la normalización social de las personas con discapacidad se formulan las cuatro leyes siguientes: Ley $5 \mathrm{I} / 2003$, de 2 de diciembre, de igualdad de oportunidades, no discriminación y accesibilidad universal de las personas con discapacidad (LIONDAU); Ley 53/2003, de ro de diciembre, sobre empleo público de discapacitados; Ley 62/2003, de 30 de diciembre, de medidas fiscales, administrativas y del orden social y la Ley 43/2006, de 29 de diciembre para la mejora del crecimiento y el empleo.

Partiendo de la legislación citada, se despliegan las siguientes normativas jurídicas que contribuyen a la inserción laboral de las personas con discapacidad:

- Real Decreto 27/2000, de I4 de enero, por el que se establecen medidas alternativas de carácter excepcional de cumplimiento de la cuota de reserva del $2 \%$ a favor de los trabajadores discapacitados en empresas de 50 o más trabajadores.

- Real Decreto 290/2004, de 20 de febrero, por el que se regulan los enclaves laborales como medida de fomento del empleo de las personas con discapacidad.

- Real Decreto 2271/2004, de 3 de diciembre, por el que se regula el acceso al empleo público y la provisión de puestos de trabajo de las personas con discapacidad.

- Real Decreto-ley ıo/2oro, de I6 de junio, de medidas urgentes para la reforma del mercado de trabajo.

- Orden TAS/736/2005, de I7 de marzo, por la que se regula la estructura y funcionamiento de la Oficina Especializada del Consejo Nacional de Discapacidad.

- Orden PRE r 822/2006, de 9 de junio, por la que se establecen criterios generales para la adaptación de tiempos adicionales en los procesos selectivos para el acceso al empleo de las personas con discapacidad.

Esta necesidad de una normativa reguladora en España tiene su referente en las crecientes necesidades a nivel europeo y, por consiguiente, en la formulación de las siguientes: 
- Directiva 2000/78/CE del Consejo, de 27 de noviembre de 2000 , relativa al establecimiento de un marco general para la igualdad de trato en el empleo y la ocupación.

- Resolución del Consejo de la Unión Europea, de 17 de junio de I999, relativa a la igualdad de oportunidades laborales de las personas con minusvalía (DOCE 02/07/99).

- Comunicación de la Comisión al Parlamento Europeo, al Consejo, al Comité Económico y Social Europeo y al Comité de Las Regiones. Estrategia europea sobre discapacidad 2010-2020: Un compromiso renovado para una Europa sin barreras. SEC I323/I324 (Comisión Europea. Bruselas. I 5.II.2010)

En este contexto europeo, España intenta dar respuesta a partir de la Estrategia global de acción para el empleo de personas con discapacidad 2008-20I2, elaborado por el Ministerio Español de Educación, Política Social y Deporte, con los siguientes objetivos: mejorar el crecimiento de la ocupación de las personas con discapacidad; dotar de coherencia y racionalidad a las políticas ocupacionales dirigidas a las personas con discapacidad; generar cambios significativos en las políticas dada la insatisfacción actual sobre la ocupación de las personas con discapacidad y conseguir ocupación de calidad para las personas con discapacidad.

Este marco legislativo ha permitido emprender iniciativas orientadas a que se cumpla la legislación vigente y a que las personas con discapacidad en España puedan ejercer sus derechos en los diferentes ámbitos de la sociedad.

Leotta (2003), en Coleman (2008), y Vilà y Pallisera (2002) ponen de relieve la importancia que tiene la inserción laboral, para todas las personas, en el proceso vital de hacerse adulto. Manifiestan que para las personas con discapacidad tener estudios superiores actúa como elemento facilitador para su acceso al mercado laboral. Sin embargo, destacan las dificultades que los estudiantes con discapacidad encuentran en las universidades, debido al escaso conocimiento del profesorado universitario sobre la discapacidad. Este desconocimiento genera una actitud poco facilitadora de la formación adecuada de estos futuros profesionales. Por todo ello se hace necesario, y prioritario, un cambio en el ámbito universitario dirigido a entender la diversidad humana. Los mismos autores consideran que una formación universitaria adecuada facilita la transición hacia la inserción laboral ordinaria. No obstante, advierten que este no es el único ámbito que ayudará, a una persona con discapacidad, a ser competente en el mercado laboral ordinario ya que también existe la conjugación entre el itinerario educativo, el itinerario personal y las políticas de apoyo vigentes en cada momento.

Vilà y Pallisera (2002) en su estudio sobre inserción laboral de titulados universitarios con gran discapacidad física, hacen énfasis en la importancia de tener un conjunto de habilidades interpersonales. Éstas coinciden, mayoritariamente, con las competencias destacadas en el estudio de UNIVERSIA -ACCENTURE (2008), estudio realizado con universitarios españoles en general. En él se pone de manifiesto la divergencia existente entre las competencias valoradas más positivamente por las empresas, las universidades y los propios estudiantes.

Vilà y Pallisera (2002) y Johnson (2006) consideran que los agentes de los servicios de apoyo a los estudiantes con discapacidad y las bolsas de trabajo de las universidades, son los profesionales que tienen asignado el papel de minimizar las barreras de todo tipo en el ámbito universitario y en la transición al mundo laboral. En la misma línea, autores como Johnson et al. (2002), David y Butler (2002), Osgood et al. (2005) y Wagner et al. (2007), explicitan que la transición de las personas con discapacidad en la vida adulta puede ser difícil porque a menudo se confunden las dificultades propias de la transición con las propias de la 
discapacidad. En esta situación es importante el papel de los profesionales que acompañan la transición. Valls, Vilà y Pallisera (2004) añaden que es imprescindible analizar todos los aspectos relacionados con la persona, y no sólo aquellos que tienen que ver con el trabajo. Así el proceso de la transición será más ajustado a sus necesidades.

Bishop y Epstein (I980), en Valls et al. (2004), muestran el papel significativo de la familia en relación a las posibilidades de formación e inserción laboral de la persona con discapacidad. Hacen referencia a la tendencia de la familia y de la propia persona con discapacidad a desajustar sus propias expectativas de la realidad. Por eso recomiendan la intervención de agentes especializados en estas cuestiones. Wagner et al. (2007) dicen que las personas con discapacidad esperan poder finalizar los estudios de secundaria, pero no muestran expectativas tan altas para finalizar con éxito los estudios universitarios.

Hernández (2000), Valls, Vilà y Pallisera (2004), Hernández et al. (2008) y Spirito y Bellini (2008) se ponen de acuerdo en que los empresarios, en el momento de incorporar personas con discapacidad a sus empresas, muestran estereotipos relacionados con sus habilidades, capacidades y competitividad así como con las adaptaciones al puesto de trabajo. Todo ello funciona como barrera al valorar al candidato. Por otra parte, los empresarios detectan que faltan candidatos universitarios con la cualificación necesaria para cubrir puestos de trabajo ya sea por no responder al perfil del puesto a cubrir y/o por la falta de competencias adecuadas (UNIVERSIA-ACCENTURE, 2008).

Un aspecto significativamente diferenciador, en la selección para un puesto de trabajo, es el tipo de discapacidad (Postuma et al., 2002). Así, los estudios realizados por Thakker y Solomon (I999), Hazer y Bedell (2000), Pearson et al. (2003), afirman que la discapacidad psíquica es la menos favorable en un proceso de selección y la física la más favorable. Sin embargo, Spirito y Bellini (2008) destacan que los entrevistadores prefieren personas sin discapacidad. En otros estudios (Furunes y Mykletun, 2007; citado en Vickers, 2008) se constata que la gestión de la diversidad en las empresas es un beneficio añadido para las mismas y representa un potencial inclusor.

Finalmente, señalamos las coincidencias de los estudios de Campoy y Pantoja (I995) y Polo (2006), al indicar que las dificultades que encuentran los titulados universitarios con discapacidad para acceder al mercado laboral ordinario son: deficiencias en su formación y falta de experiencia; excesiva protección familiar; prejuicios sociales; falta de sensibilización en pequeñas y medianas empresas; creencias erróneas referidas a su propia discapacidad y falta de accesibilidad en las empresas.

\section{Objetivos}

Nuestro interés es aportar información a la sociedad en general y, en concreto, a los agentes empleadores y a la comunidad educativa universitaria, que contribuya a favorecer el pleno desarrollo del proyecto de vida laboral al que aspiran los titulados universitarios con discapacidad del estado español. Los objetivos que nos hemos planteado son:

- Conocer la experiencia de los titulados universitarios españoles con discapacidad, en relación a su formación para acceder al mercado laboral ordinario.

- Identificar los factores percibidos como obstáculos y los percibidos como facilitadores por parte de los titulados universitarios españoles con discapacidad, en el momento de su inserción al mercado laboral ordinario.

- Conocer la percepción de las empresas acerca de los titulados universitarios españoles con discapacidad, en el momento de su inserción al mercado laboral ordinario. 
- Plantear propuestas de mejora para favorecer la inclusión, al mercado laboral, de los titulados universitarios españoles con discapacidad.

\section{Metodología}

La información se ha obtenido a partir de los cuestionarios elaborados específicamente para esta investigación, con preguntas cerradas y abiertas.

Las respuestas a las preguntas cerradas han sido tratadas informáticamente mediante una hoja de cálculo. Se efectuó un análisis descriptivo de los datos.

El análisis de las respuestas a las preguntas abiertas se ha llevado a cabo a partir de crear un sistema de categorías para cada apartado a analizar. Para la elaboración del sistema de categorías se ha seguido el proceso inductivo. Hemos velado por que las categorías elaboradas sean exhaustivas y mutuamente excluyentes, cumpliendo así los requisitos propios de todo sistema de categorización (Buendía, Colas y Hernández, I997).

\subsection{Procedimiento y participantes}

La información para realizar este estudio se recogió durante el primer trimestre del 20 IO. Se trata de un estudio de ámbito nacional en el que se ha incorporado cuatro grupos de sujetos bien diferenciados: estudiantes universitarios con discapacidad; servicios de apoyo a los estudiantes universitarios con discapacidad de las universidades españolas; titulados universitarios españoles con discapacidad y empresas.

Dado que, una buena parte de la investigación se ha dirigido a estudiantes y a titulados universitarios españoles con discapacidad y que, por la ley de protección de datos (Real Decreto
I720/2007) no podíamos acceder directamente a estos grupos, se ha contactado con los estudiantes mediante los servicios de apoyo de las universidades para que éstas actuaran como intermediarios. Las asociaciones de personas con discapacidad y distintas fundaciones involucradas en la inserción laboral de titulados con discapacidad, nos ayudaron a acceder al grupo de titulados universitarios. Las direcciones de dichas asociaciones y fundaciones fueron extraídas de la base de datos del Centro Español de Documentación sobre Discapacidad (CEDD). Éste fue el procedimiento para hacer llegar a cada grupo (estudiantes universitarios con discapacidad y titulados universitarios con discapacidad) la invitación a participar. Por este motivo, no podemos concretar el número de personas que han sido invitadas. Solamente podemos referirnos al total de sujetos que aceptaron formar parte del estudio y que ha configurado la muestra participante de estudiantes por una parte y la de titulados por otra.

En cambio, sí disponíamos de la relación de las universidades con servicio de apoyo a los estudiantes con discapacidad.

Dado que el estudio también estaba orientado a conocer la percepción de las empresas españolas en relación a la inserción laboral de los titulados universitarios con discapacidad, para solicitar su participación accedimos a la base de datos específica para emplear a titulados universitarios con y sin discapacidad de UNIVERSIA y Fundación UNIVERSIA.

\subsubsection{Estudiantes universitarios con discapacidad}

Se consideró oportuno incorporar solamente a los estudiantes que se encuentran en los dos últimos cursos de sus estudios. En este momento de su formación podían ya tener elementos de referencia sobre sus posibilidades laborales y, lógicamente, más conocimiento en relación a su formación universitaria.

La muestra real de este grupo quedó configurada por 77 estudiantes. De éstos, 44 son mujeres y 
33 hombres con una media de edad de 30 años. Su residencia habitual representa a la mayoría de las Comunidades Autónomas.

\subsubsection{Servicios de Apoyo a los estudiantes de las universidades}

Nos pusimos en contacto con los responsables de los Servicios de Apoyo de 78 universidades españolas. Éstas representaban todas las que, en el momento de la recogida de información (marzo de 20Io), disponían de Servicios de Apoyo para los estudiantes con discapacidad. Recibimos respuesta de I9 Servicios.

\subsubsection{Titulados universitarios españoles con discapacidad}

El grupo participante quedó configurado por 687 titulados universitarios españoles con discapacidad. Éstos quedan repartidos en dos subgrupos:

- 661 titulados universitarios con experiencia laboral

- 26 titulados universitarios sin experiencia laboral

Puesto que la participación de los titulados sin experiencia laboral ha sido muy reducida hemos decidido no incluirlos como muestra real.

\section{Gráfico 1. Residencia habitual de los titulados universitarios con discapacidad de la muestra (2010).} Valores absolutos

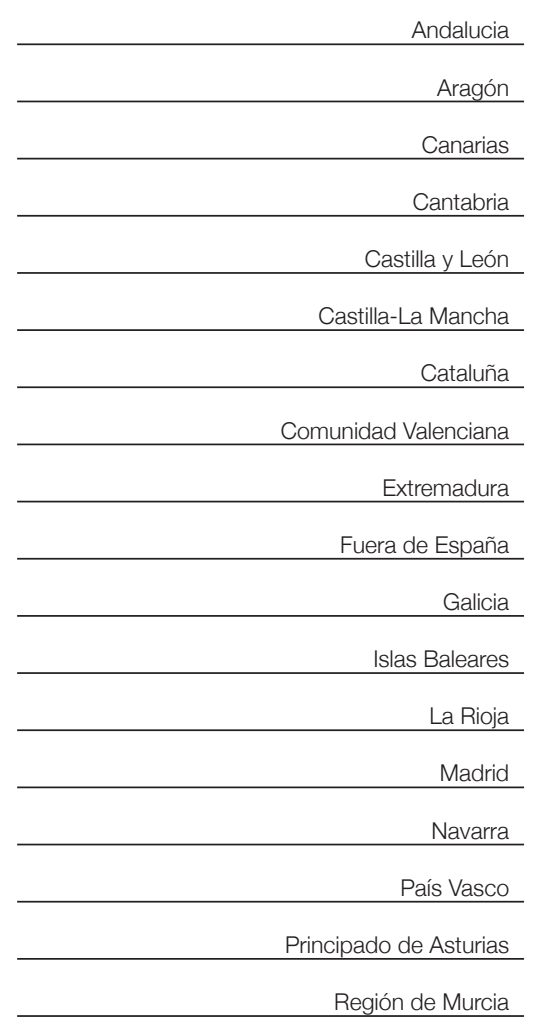

Fuente: Elaboración propia. 
La muestra real de este apartado es de 661 titulados universitarios con experiencia laboral. De éstos, 358 son mujeres y 303 hombres con una media de edad de 37 años. Su residencia habitual representa a todas las comunidades autónomas como muestra el Gráfico I.

\subsubsection{Empresas}

La muestra invitada fue de 580 empresas. De éstas recibimos respuesta de I6. La muestra real es:

- 4 empresas españolas con experiencia en la incorporación, entre sus empleados, de titulados universitarios con discapacidad.

- 12 empresas españolas sin experiencia en la incorporación, entre sus empleados, de titulados universitarios con discapacidad.

Todas estas empresas pertenecen a la tipología de organización empresarial privada y mayoritariamente vinculadas al sector terciario.

Las 4 empresas con experiencia en su plantilla de titulados universitarios con discapacidad, se sitúan entre aquellas que tienen más de 250 trabajadores y son del ámbito internacional. Y las I 2 que no tienen ésta experiencia representan a los diferentes tipos de tamaño empresarial (micro, pequeña, mediana y gran empresa) y también a todos los ámbitos geográficos (local, nacional e internacional).

\subsection{Instrumentos}

La información proporcionada por los participantes se ha obtenido a través de cuestionarios online elaborados específicamente para esta investigación.

Se dispuso de un cuestionario específico para cada uno de los grupos. Después de revisar la literatura disponible y de acuerdo con la finalidad y los objetivos del estudio, se diseñaron los apartados de cada cuestionario. Posteriormente se sometieron a juicio de expertos. Actuaron como expertos seis profesores universitarios e investigadores especialistas en temas de discapacidad, inserción laboral y metodologías de investigación. Después de tener en cuenta sus sugerencias, se elaboró la versión definitiva de cada uno de los cuestionarios. Posteriormente se realizó una prueba piloto.

La primera parte de todos los cuestionarios recoge datos de tipo demográfico. El cuestionario para los estudiantes universitarios y los cuestionarios para los titulados universitarios se completan con los mismos apartados. No obstante, hay que tener en cuenta que para algunos contenidos al grupo de estudiantes se le pedía que respondiera en base a sus expectativas y al grupo de titulados que lo hiciera según su experiencia. Los apartados son: elección de los estudios universitarios; formación universitaria recibida; servicios universitarios de inserción laboral; acceso en el mercado laboral; legislación y administración; concesión de apoyos durante el desarrollo profesional; actitudes y creencias, hacia la discapacidad, por parte de los empleadores y de los empleados. Finalmente, un apartado de observaciones. En el cuestionario para los titulados se incorpora un apartado sobre promoción y satisfacción laboral.

El cuestionario para los dos grupos de empresas está formado por los mismos apartados, a pesar de tener un enfoque distinto para cada uno. Para el grupo de empresas que cuenta o ha contado, entre sus empleados, con titulados universitarios con discapacidad se pedía que respondieran según su experiencia, y para aquellas empresas sin esta experiencia se les pedía que respondieran en base a sus creencias. Los apartados de este cuestionario son: formación universitaria de los empleados; acceso al mercado laboral y desarrollo profesional de los titulados universitarios con discapacidad; percepción de las actitudes y creencias hacia la discapacidad por parte de los empleadores y de los compañeros de trabajo y finalmente, observaciones.

El cuestionario dirigido a las universidades, y en concreto, a los Servicios de Apoyo a los estudiantes con discapacidad incluye los apartados siguientes: datos de la universidad; datos sobre los estudiantes con discapacidad de su universidad que están cursando los dos 
últimos cursos académicos; datos sobre los titulados universitarios con discapacidad; opinión sobre la inserción laboral de los estudiantes con discapacidad y para finalizar, observaciones.

Se ha puesto a disposición de los participantes los resultados del estudio.

\subsection{Limitaciones del estudio}

Queremos dejar constancia de las limitaciones que hemos detectado a lo largo de la investigación y que creemos necesario tener en cuenta en el momento de generalizar los resultados. Por una parte, desconocemos el número total de titulados universitarios con discapacidad españoles por lo que no podemos conocer la representatividad de la muestra. Por otra parte, el número de empresas que ha decidido participar ha sido muy bajo, lo que ha dificultado cumplir plenamente con uno de los objetivos del estudio.

Otra limitación importante ha sido la escasez de investigaciones sobre el tema concreto de la inserción laboral de los titulados universitarios con discapacidad en entornos laborales ordinarios, lo que nos ha impedido contrastar los resultados de nuestro estudio con los de otras investigaciones similares.

A partir de las limitaciones expuestas entendemos que nuestro trabajo tiene la importancia y el valor de un primer estudio exploratorio sobre el estado actual del tema.

\section{Resultados}

4.1. Resultados de los estudiantes universitarios con discapacidad

En el estudio se observa que el tipo de discapacidad que predomina es la motriz $(55,84 \%)$, seguido de la auditiva (I $2,99 \%)$, la orgánica $(9,09 \%)$, la visual y la psíquica ${ }^{2}$

2. Entendemos por discapacidad psíquica trastornos y
$(7,79 \%)$ respectivamente y, finalmente, la múltiple $(6,49 \%)$.

La media del grado de discapacidad de este tipo de estudiantes se sitúa, de acuerdo con el certificado de minusvalía, en el 53,32\%.

Entre las ramas de estudio escogida, por este grupo de estudiantes universitarios con discapacidad, destaca de manera significativa los estudios de ciencias sociales y jurídicas $(55,84 \%)$.

\subsubsection{Elección de los estudios universitarios}

Referente a la orientación profesional, antes del acceso a la universidad, el 63,63\% de los estudiantes opina que no tuvo una buena orientación profesional.

En relación a la elección de los estudios universitarios y la propia discapacidad, sólo el 29,87\% manifiesta que los estudios universitarios escogidos estuvieron condicionados por su situación de persona con discapacidad. El resto opinó que su discapacidad no influyó en la elección.

Un 75,32\%, de estudiantes no les influyó saber que en el mundo laboral dispondría de los apoyos necesarios para el desarrollo de su vida profesional.

La t abla I muestra los resultados de la opinión de los estudiantes con discapacidad al ser preguntados sobre qué aspectos, desde su punto de vista, podrían favorecer a las personas con discapacidad una correcta elección de los estudios universitarios.

Los estudiantes universitarios con discapacidad destacan, en un $28, \mathrm{I} \%$, la necesidad de una orientación pre-universitaria que les permita la elección de los estudios universitarios desde una perspectiva de futuro laboral normalizado.

síndromes como por ejemplo: síndrome de Asperger, Trastorno Bipolar, Esquizofrenia, etc. 
Tabla 1. Aspectos que favorecen una correcta elección de los estudios universitarios según los estudiantes con discapacidad (2010). Porcentaje sobre el total de respuestas

\begin{tabular}{|c|c|}
\hline \multicolumn{2}{|l|}{ Elección de los estudios universitarios } \\
\hline Categorías & $\%$ \\
\hline Orientadores profesionales que favorezcan la inserción laboral normalizada & 28,1 \\
\hline Apoyos para desarrollar el currículum de forma normalizada & 25,6 \\
\hline Conocer los propios límites y las habilidades necesarias para la carrera & 10,7 \\
\hline Motivación por los estudios & 10,7 \\
\hline Accesibilidad de edificios y adaptaciones de puestos de trabajo & 7,4 \\
\hline Conocer los recursos que pueden facilitar el desarrollo de la profesión & 5,8 \\
\hline Contratación normalizada & 4,1 \\
\hline Nada que se diferencie de los demás estudiantes & 4,1 \\
\hline Aplicación de la legislación & 2,5 \\
\hline No sabe qué podría favorecer una correcta elección & 0,8 \\
\hline TOTAL & 100 \\
\hline
\end{tabular}

Fuente: Elaboración propia.

\subsubsection{Formación universitaria actual}

El 76,62\% de los estudiantes universitarios con discapacidad cree que tener estudios universitarios les facilitará la entrada al mercado laboral mejor que si no los tuviera.

Los estudiantes opinan que las universidades les facilitan los apoyos necesarios para adquirir las siguientes competencias: habilidades comunicativas $(58,74 \%)$, habilidad para trabajar de forma autónoma y tomar decisiones $(67,53 \%)$, iniciativa y espíritu emprendedor $(59,74 \%)$, preocupación por hacer las cosas bien $(63,64 \%)$, motivación, entusiasmo y ganas de aprender $(58,44 \%)$, capacidad para trabajar bajo presión $(55,84 \%)$, habilidades interpersonales $(55,85 \%)$, capacidad para adaptarse a nuevas situaciones $(55,85 \%)$, manejo de las nuevas tecnologías $(63,63 \%)$ y habilidades de búsqueda y gestión de la información $(63,63 \%)$. Por otra parte, consideran que la universidad no facilita, suficientemente los apoyos necesarios para adquirir las competencias siguientes: dominio de la lengua inglesa ( $8 \mathrm{I}, 8 \mathrm{I} \%$ ), capacidad de organizar y planificar $(55,84 \%)$, potencial de liderazgo $(67,53 \%)$, capacidad de negociación $(5 \mathrm{I}, 95 \%)$ y capacidad para generar nuevas ideas $(53,24 \%)$.

\subsubsection{Opinión sobre los Servicios Universitarios de inserción laboral}

El 94,8 I \% de los estudiantes con discapacidad opina que es imprescindible que las universidades dispongan de servicios para orientarlos en el momento de la inserción laboral. Por otra parte, el 97,40\% de estos estudiantes considera que las redes de inserción laboral de las universidades deberían informarlos durante los últimos cursos de sus estudios de las posibilidades del mercado laboral. 
4.1.4. Expectativas de formación a lo largo de la vida profesional y de acceso al mercado laboral relacionado con los estudios cursados

Un $67,53 \%$ de los estudiantes con discapacidad cree que les será fácil actualizar su formación a lo largo de su vida laboral.

Los estudiantes con discapacidad señalan, un $53,25 \%$, que les será más difícil el acceso al mercado laboral que a sus compañeros sin discapacidad. Consideran, en un 59,74\%, que existen factores que obstaculizan la inserción laboral de los universitarios con discapacidad. $\mathrm{Al}$ ser preguntados por estos factores hemos obtenido los resultados expuestos en la Tabla 2.

Tabla 2. Factores obstaculizadores de la inserción laboral de los universitarios con discapacidad según los estudiantes con discapacidad (2010). Porcentaje sobre el total de respuestas

\begin{tabular}{|l|c|}
\hline \multicolumn{2}{|c|}{ Factores obstaculizadores } \\
\hline Categorías & $\%$ \\
\hline Prejuicios & 32,8 \\
\hline $\begin{array}{l}\text { Limitaciones auto-atribuidas a la } \\
\text { propia discapacidad }\end{array}$ & 19,7 \\
\hline $\begin{array}{l}\text { Falta de accesibilidad, adaptaciones y } \\
\text { apoyos en el trabajo }\end{array}$ & 18,0 \\
\hline $\begin{array}{l}\text { Percepción de la discapacidad por } \\
\text { parte de los empresarios/ RR.HH. }\end{array}$ & 14,8 \\
\hline $\begin{array}{l}\text { No conocer los límites de la propia } \\
\text { discapacidad }\end{array}$ & 4,9 \\
\hline $\begin{array}{l}\text { Creencia de que existen trabajos } \\
\text { inalcanzables }\end{array}$ & 3,3 \\
\hline $\begin{array}{l}\text { Falta de ayudas por parte de la } \\
\text { administración }\end{array}$ & 3,3 \\
\hline $\begin{array}{l}\text { Desconocimiento de la legislación } \\
\text { sobre empleo y discapacidad }\end{array}$ & 1,6 \\
\hline $\begin{array}{l}\text { Pocas personas con discapacidad } \\
\text { que acceden a los estudios } \\
\text { universitarios }\end{array}$ & 1,6 \\
\hline TOTAL & 100 \\
\hline
\end{tabular}

Fuente: Elaboración propia.
El principal factor obstaculizador manifestado por los estudiantes universitarios con discapacidad es el prejuicio hacia la misma $(32,8 \%)$. Éste prejuicio se refiere a las barreras mentales que predominan en la sociedad.

Este grupo de estudiantes considera, en un $53,25 \%$, que existen factores que facilitan su inserción laboral. Al ser preguntados por estos factores hemos obtenido los resultados expuestos en la Tabla 3 .

Tabla 3. Factores facilitadores de la inserción laboral de los universitarios con discapacidad según los estudiantes con discapacidad (2010). Porcentaje sobre el total de respuestas

\begin{tabular}{|l|c|}
\hline \multicolumn{2}{|c|}{ Factores facilitadores } \\
\hline Categorías & $\%$ \\
\hline Optimización de la legislación & 51,0 \\
\hline Buena formación universitaria & 14,3 \\
\hline $\begin{array}{l}\text { Apoyo de las asociaciones y } \\
\text { fundaciones para la inserción laboral }\end{array}$ & 12,2 \\
\hline $\begin{array}{l}\text { Percepción de la discapacidad por } \\
\text { parte de los empresarios }\end{array}$ & 8,2 \\
\hline $\begin{array}{l}\text { Características del ámbito laboral } \\
\text { elegido }\end{array}$ & 6,1 \\
\hline $\begin{array}{l}\text { Accesibilidad en el puesto de trabajo } \\
\text { Oferta y demanda laboral acorde con }\end{array}$ & $\mathbf{6 , 1}$ \\
\hline $\begin{array}{l}\text { los propios estudios } \\
\text { TotaL }\end{array}$ & 2,0 \\
\hline
\end{tabular}

Fuente: Elaboración propia.

Se observa que el principal factor que facilitaría el acceso al mercado laboral ordinario sería que, por parte de las empresas, hubiera un mayor conocimiento y aplicación de la legislación sobre el empleo de las personas con discapacidad (5 $1 \%)$. 


\subsubsection{Legislación en relación a la inserción laboral}

Los estudiantes universitarios con discapacidad expresan, en un $63,64 \%$, no tener conocimiento sobre sus derechos para poder realizar una adecuada inserción laboral.

\subsection{Servicios Universitarios de Apoyo a los estudiantes con discapacidad}

Los resultados obtenidos de los servicios nos indican que el 73,68\% de ellos no dispone de ningún servicio específico de inserción laboral para titulados con discapacidad en su universidad.

Estos servicios perciben como factores obstaculizadores, para la inserción laboral de los titulados con discapacidad, los que se muestran en la Tabla 4 .

\section{Tabla 4. Factores obstaculizadores percibidos por los Servicios Universitarios de Apoyo (2010). Porcentaje sobre el total de respuestas}

\begin{tabular}{|l|c|}
\hline \multicolumn{2}{|c|}{ Factores obstaculizadores } \\
\hline Categorías & $\%$ \\
\hline $\begin{array}{l}\text { Percepción de la discapacidad por } \\
\text { parte de los empresarios }\end{array}$ & 21,0 \\
\hline $\begin{array}{l}\text { Poca información y sensibilización } \\
\text { social sobre la discapacidad }\end{array}$ & 18,0 \\
\hline Características de la discapacidad & 18,0 \\
\hline $\begin{array}{l}\text { Falta de accesibilidad y de } \\
\text { adaptaciones en el trabajo }\end{array}$ & 18,0 \\
\hline Actitud de la familia & 8,0 \\
\hline Apoyo de la administración & 8,0 \\
\hline $\begin{array}{l}\text { Falta de formación de los orientadores } \\
\text { al empleo }\end{array}$ & 3,0 \\
\hline $\begin{array}{l}\text { Oferta y demanda laboral acorde con } \\
\text { los propios estudios }\end{array}$ & 3,0 \\
\hline $\begin{array}{l}\text { No disponer de una base de datos } \\
\text { específica }\end{array}$ & 3,0 \\
\hline TOTAL & 100 \\
\hline
\end{tabular}

Fuente: Elaboración propia.
Del total de respuestas, observamos que un 2I \% señala como principal factor obstaculizador la percepción poco ajustada de la discapacidad por parte de los empresarios. Al especificarlo los servicios opinan que: existen demasiadas ofertas de trabajo vinculadas a la discapacidad; un gran desconocimiento de las capacidades de los titulados universitarios con discapacidad; demasiados prejuicios y miedos en relación a la discapacidad, especialmente, hacia las enfermedades mentales; y escasa sensibilidad social.

Por otra parte, los servicios perciben como factores facilitadores, para la inserción laboral de los titulados con discapacidad, los que se muestran en la Tabla 5 .

Tabla 5. Factores facilitadores percibidos por los Servicios Universitarios de Apoyo (2010).

Porcentaje sobre el total de respuestas

\begin{tabular}{|l|c|}
\hline \multicolumn{2}{|c|}{ Factores facilitadores } \\
\hline Categorías & $\%$ \\
\hline $\begin{array}{l}\text { Información y orientación para la } \\
\text { transición laboral }\end{array}$ & 20,0 \\
\hline $\begin{array}{l}\text { Más instituciones específicas y mayor } \\
\text { coordinación con las universidades }\end{array}$ & 17,5 \\
\hline Apoyo de la administración & 15,0 \\
\hline $\begin{array}{l}\text { Más información y sensibilización } \\
\text { social sobre la discapacidad }\end{array}$ & 7,5 \\
\hline Formación para la inserción laboral & 7,5 \\
\hline $\begin{array}{l}\text { Percepción de la discapacidad como } \\
\text { valor añadido para la empresa }\end{array}$ & 7,5 \\
\hline Características de la discapacidad & 7,5 \\
\hline $\begin{array}{l}\text { Más recursos materiales y } \\
\text { económicos para mejorar la } \\
\text { educación de los estudiantes } \\
\text { universitarios con discapacidad }\end{array}$ & 2,0 \\
\hline $\begin{array}{l}\text { Disponer de una base de datos } \\
\text { específica (estudiantes con } \\
\text { discapacidad) }\end{array}$ & 5,0 \\
\hline Actitud de la familia & 100 \\
\hline $\begin{array}{l}\text { Oferta y demanda laboral acorde con } \\
\text { los propios estudios }\end{array}$ & 2,5 \\
\hline $\begin{array}{l}\text { Nuevas tecnologías aplicadas al } \\
\text { puesto de trabajo }\end{array}$ & 2,5 \\
\hline TotAL & 2,5 \\
\hline
\end{tabular}

Fuente: Elaboración propia. 
Del total de respuestas de los servicios participantes, observamos que un $20 \%$ ve como principal factor facilitador la información y orientación para la transición laboral.

\subsection{Titulados universitarios con discapacidad} con experiencia en el mercado laboral ordinario

Características significativas del grupo de los titulados universitarios con discapacidad que forman parte de nuestro estudio.

Observamos en el Gráfico 2 que la tipología de discapacidad que predomina es la motriz
$(48,4 \mathrm{I} \%)$, seguida de la visual $(\mathrm{I} 4,67 \%)$, la auditiva ( ( 2,7 I \%), la múltiple ( $10,74 \%)$, la orgánica $(6,66 \%)$, la psíquica $(6,20 \%)$ $\mathrm{y}$, finalmente, un grupo sin especificar $(0,6 \mathrm{I} \%)$.

La media del grado de discapacidad se sitúa, de acuerdo con el certificado de minusvalía, en el $56,62 \%$.

En el Gráfico 3 se observa que la rama de Ciencias Sociales y Jurídicas es la más cursada por los titulados universitarios con discapacidad destacando por encima de las otras en un $62,93 \%$.

Gráfico 2. Tipo de discapacidad de los titulados universitarios (2010). Porcentajes

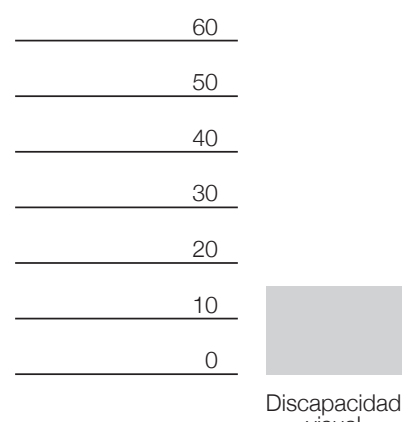

visual

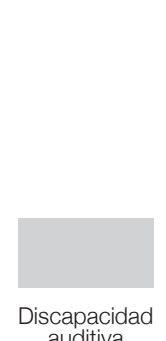
auditiva

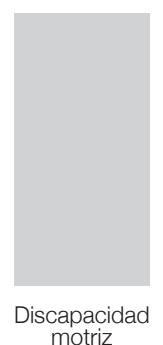
motriz

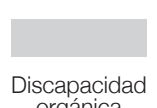
orgánica

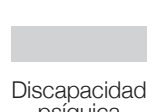
psíquica

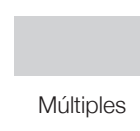

No especificadas

Fuente: Elaboración propia.

Gráfico 3. Rama de estudios cursada por los titulados universitarios con discapacidad (2010). Porcentajes
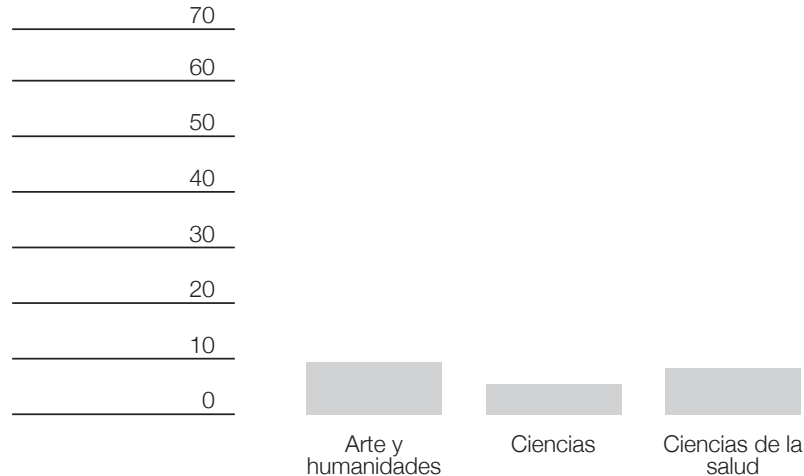

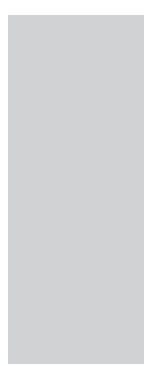

Ciencias sociales y jurídicas

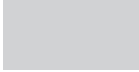

Ingenería y arquitectura

Fuente: Elaboración propia. 
La situación laboral de este grupo, en el momento de responder el cuestionario, era activa en un $69,59 \%$. El resto tiene experiencia en el mundo laboral aunque en aquel momento no estaba trabajando.

\subsubsection{Elección de los estudios universitarios}

En relación a la orientación profesional recibida antes de acceder a la universidad por parte de los centros educativos no universitarios, los titulados manifiestan en un 50,83\% que no tuvieron este tipo de orientación. Los que sí la tuvieron indican, en un 33,89\%, estar satisfechos de ella y un I $5,28 \%$ opina no haber obtenido este grado de satisfacción.

Estos titulados expresan que las opciones escogidas para el acceso a los estudios universitarios no estuvieron condicionadas por su situación de persona con discapacidad $(75,34 \%)$.

\subsubsection{Formación universitaria recibida}

Los titulados consideran que, el hecho de tener unos estudios universitarios, como personas con discapacidad, les ha facilitado el acceso al mundo laboral (7I,86\%).

Las prácticas profesionales durante los estudios universitarios son para la mayoría de los titulados con discapacidad $(63,39 \%)$, indistintamente de la tipología de la misma, una experiencia positiva que contribuye adecuadamente en su desarrollo profesional.

Mostramos los resultados en relación al grado de apoyo recibido, durante la formación universitaria, para poder adquirir y desarrollar las distintas competencias profesionales (Gráfico 4).

Según la opinión de este grupo de titulados, observamos que las competencias profesionales en las que las universidades ofrecen menor grado de apoyo son: dominio de la lengua inglesa; potencial de liderazgo, capacidad de influir y motivar a otros; manejo del ordenador; iniciativa y espíritu emprendedor; capacidad de negociación, saber convencer y aceptar otros puntos de vista; capacidad para generar nuevas ideas, creatividad e innovación; habilidades comunicativas; y habilidad para trabajar de forma autónoma y tomar decisiones.

Observamos que este grupo considera elevado y/o suficiente el grado de apoyo ofrecido por la universidad para desarrollar: preocupación por la calidad; motivación, entusiasmo y ganas de aprender; capacidad de organizar y planificar, saber administrar el tiempo; habilidades de búsqueda y gestión de información; habilidades interpersonales, saber relacionarse con otros; capacidad de adaptarse a nuevas situaciones, flexibilidad; y capacidad de trabajar bajo presión.

\subsubsection{Servicios Universitarios de inserción laboral}

Los titulados universitarios destacan, en un $90,47 \%$, que el servicio de orientación e inserción laboral de la universidad no tuvo ningún papel significativo para acceder como persona con discapacidad a un puesto de trabajo. A su vez, el 86,99\% considera que además de la bolsa de trabajo ordinaria es imprescindible que las universidades dispongan de servicios para orientar a los titulados con discapacidad en el momento de la inserción laboral.

\subsubsection{Acceso profesional en el mercado laboral}

Los resultados indican que la mayoría de los titulados universitarios con discapacidad logran insertarse en el mercado laboral, después de obtener su titulación universitaria, en el primer año de haber terminado sus estudios (Gráfico 5).

Los titulados informan que las vías de acceso al mercado laboral más útiles para encontrar trabajo han sido en orden de eficacia las siguientes: contactos personales; ofertas de empleos de asociaciones para personas con discapacidad; envíos espontáneos del currículum 
Gráfico 4. Opinión de los titulados universitarios con discapacidad respecto a los apoyos recibidos en la universidad para el desarrollo de sus competencias profesionales (2010). Porcentajes

Habilidades comunicativas

Dominio de la lengua inglesa

Habilidad para trabajar de forma autónoma y tomar decisiones

Iniciativa y espíritu emprendedor

Preocupación por la calidad, por hacer bien las cosas

Motivación, entusiasmo y ganas de aprender

Capacidad de organizar y planificar, saber administrar el tiempo

Capacidad de trabajar bajo presión

Potencial de liderazgo, capacidad de influir y motivar en otros

Capacidad de negociación, saber convencer y aceptar otros puntos de vista

Habilidades interpersonales, saber relacionarse con otros

Capacidad para adaptarse a nuevas situaciones, flexibilidad

Capacidad para generar nuevas ideas, creatividad e innovación

Manejo del ordenador

Habilidades de búsqueda y gestión de información

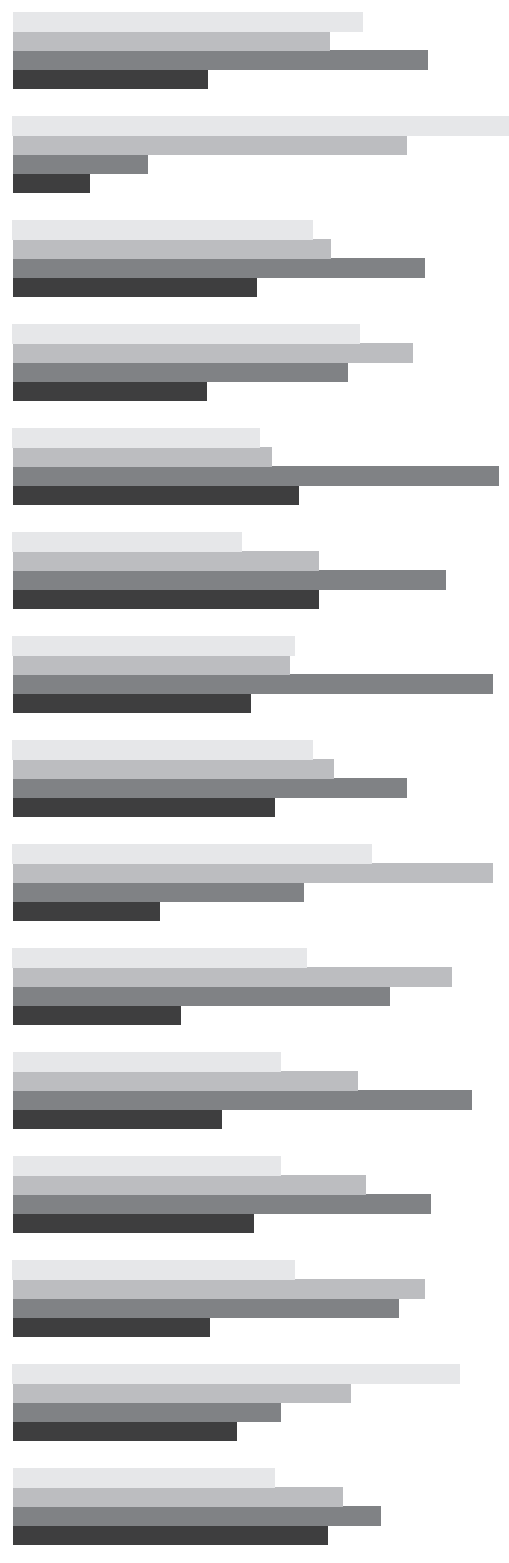

10

20

30

40

50

60
- Nada
-1. Poco
Bastante
Mucho

Fuente: Elaboración propia. 
Gráfico 5. Tiempo en que los titulados universitarios con discapacidad tardan en encontrar su primer trabajo (2010). Porcentajes

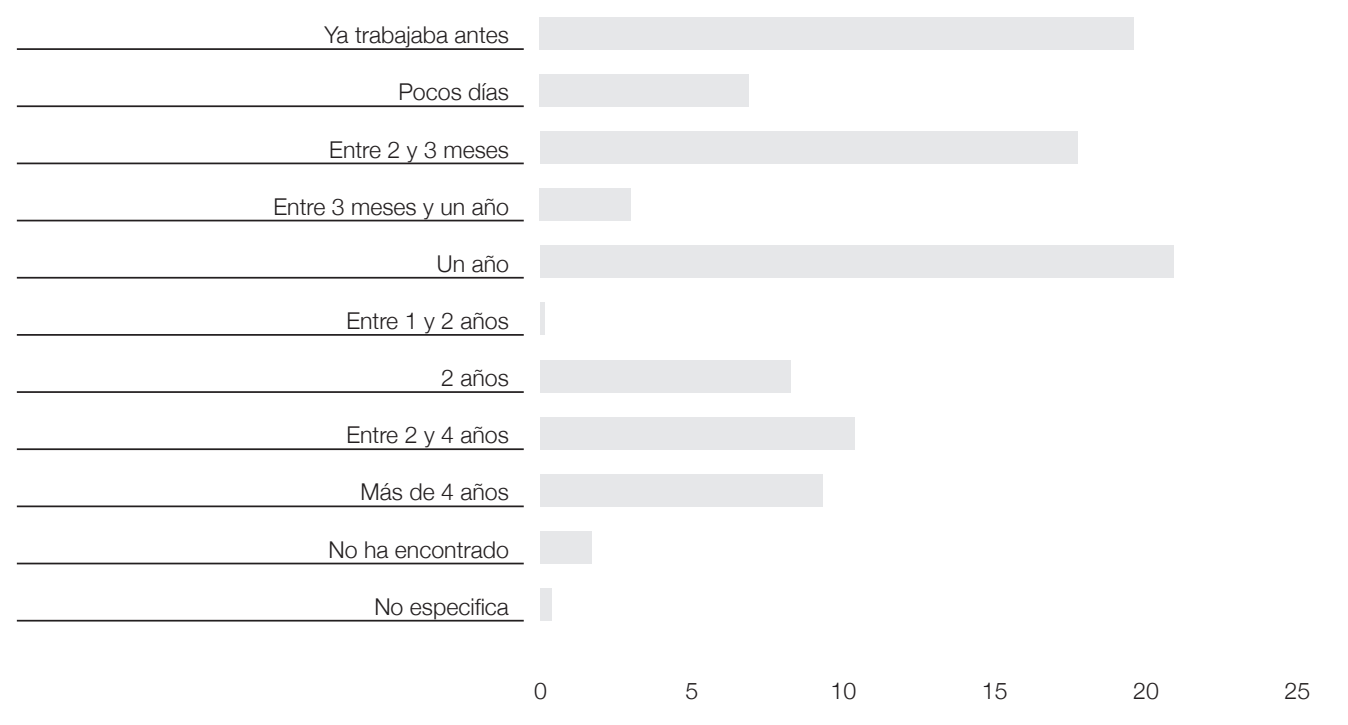

Fuente: Elaboración propia.

vitae por correo postal o electrónico; portales de empleo de internet y el servicio público de empleo estatal (INEM).

En relación al tipo de organización empresarial al que están o han estado vinculados los titulados universitarios con discapacidad se constata que un $37,52 \%$ manifiesta su vinculación a una organización empresarial pública. Un $67,78 \%$ su vinculación a una organización empresarial privada por cuenta ajena. Y un I I, $50 \%$ manifiesta su vinculación a una organización empresarial privada por cuenta propia.

Se destaca que de un total de 66I titulados universitarios con discapacidad el 80, I $8 \%$ tiene experiencia laboral relacionada con sus estudios universitarios.

De acuerdo con su experiencia los titulados $(76,25 \%)$ manifiestan que, en el momento de elegir un candidato por parte de la empresa, la discapacidad es un factor negativo frente a la calidad del currículum vitae. Consideran, en un $59,76 \%$, que su condición de personas con discapacidad les ha hecho más difícil el acceso al mercado laboral que a sus compañeros de estudio sin discapacidad.

\subsubsection{Factores obstaculizadores para la inserción laboral}

A partir del análisis del contenido de las respuestas abiertas del cuestionario de los titulados exponemos en la Tabla 6 los resultados que permiten conocer los obstáculos que, según los titulados, dificultan su inserción laboral.

Los resultados indican que los titulados universitarios con discapacidad consideran como principal factor obstaculizador, para el acceso al mercado laboral ordinario, la percepción de los empleadores sobre la discapacidad $(44,8 \%)$. Afirman que existe falta de información sobre la discapacidad que provoca estigmatización de la misma, sobre todo, en la discapacidad psíquica. 
Tabla 6. Factores obstaculizadores para la inserción laboral según los titulados universitarios con discapacidad (2010). Porcentaje sobre el total de respuestas

\begin{tabular}{|l|c|}
\hline \multicolumn{2}{|c|}{ Factores obstaculizadores } \\
\hline Categorías & $\%$ \\
\hline $\begin{array}{l}\text { Percepción de la discapacidad por } \\
\text { parte de los empresarios/ Recursos } \\
\text { Humanos (RR.HH.) }\end{array}$ & 44,8 \\
\hline $\begin{array}{l}\text { Prejuicios de la sociedad } \\
\text { Falta de accesibilidad, adaptaciones } \\
\text { y apoyos }\end{array}$ & 13,5 \\
\hline $\begin{array}{l}\text { Limitaciones de la propia } \\
\text { discapacidad }\end{array}$ & 16,0 \\
\hline $\begin{array}{l}\text { Falta de orientación profesional e } \\
\text { información laboral } \\
\text { inserción laboral }\end{array}$ & 12,4 \\
\hline $\begin{array}{l}\text { Falta de compromiso real por parte de } \\
\text { la administración }\end{array}$ & 3,2 \\
\hline sobre empleo y discapacidad & 2,8 \\
\hline
\end{tabular}

Fuente: Elaboración propia.

Esta estigmatización induce al empresario a no aceptar currículos donde se explicita la situación de discapacidad del candidato al puesto de trabajo, a ofertar trabajos de un nivel inferior al de su formación con expectativas negativas de promoción y a atribuirle un supuesto bajo rendimiento por culpa de bajas laborales. Esto según sus propias justificaciones dificulta la libre manifestación de su discapacidad en el proceso de selección laboral.

\subsubsection{Factores facilitadores para la inserción laboral}

Del análisis del contenido de las respuestas abiertas del cuestionario de los titulados exponemos en la Tabla 7 los resultados que permiten conocer los obstáculos que, según los titulados, dificultan su inserción laboral.

Tabla 7. Factores facilitadores para la inserción laboral según los titulados universitarios con discapacidad (2010). Porcentaje sobre el total de respuestas

\begin{tabular}{|l|c|}
\hline \multicolumn{2}{|c|}{ Factores facilitadores } \\
\hline Categorías & $\%$ \\
\hline $\begin{array}{l}\text { Conocimiento, cumplimiento y/o } \\
\text { adaptación de la legislación sobre } \\
\text { empleo y medidas sancionadoras }\end{array}$ & 37,8 \\
\hline $\begin{array}{l}\text { Percepción sobre la discapacidad por } \\
\text { parte de los empresarios/ Recursos } \\
\text { Humanos (RR.HH.) }\end{array}$ & 12,4 \\
\hline $\begin{array}{l}\text { Formación adecuada para desarrollo } \\
\text { laboral y prácticas laborales }\end{array}$ & 10,6 \\
\hline $\begin{array}{l}\text { Las características de la propia } \\
\text { persona }\end{array}$ & 9,1 \\
\hline $\begin{array}{l}\text { Nada lo facilita ( trabajos } \\
\text { discriminatorios/ caridad) }\end{array}$ & 8,9 \\
\hline Empleo público & 7,3 \\
\hline $\begin{array}{l}\text { Cumplimiento real de la } \\
\text { administración/campañas } \\
\text { informativas para el empleo de } \\
\text { personas con discapacidad }\end{array}$ & 100 \\
\hline $\begin{array}{l}\text { Existencia de accesibilidad, } \\
\text { adaptaciones y apoyos en el mundo } \\
\text { laboral }\end{array}$ & $\begin{array}{l}\text { Asesoramiento y orientación laboral } \\
\text { (asociaciones, administración, etc.) a } \\
\text { los candidatos y a las empresas }\end{array}$ \\
\hline No hay obstáculos específicos & 1,0 \\
\hline TotAL & 1,6 \\
\hline
\end{tabular}

Fuente: Elaboración propia. 
Los resultados nos indican que los titulados universitarios con discapacidad perciben como principal factor facilitador el conocimiento, cumplimiento y/o adaptación, por parte de las empresas, de la legislación sobre empleo y medidas sancionadoras $(37,8 \%)$.

\subsubsection{Apoyos por parte de la administración pública y de las empresas privadas para la inserción laboral}

Un 66,4I \% de los titulados dice tener suficiente conocimiento de la legislación vigente para poder ejercer sus derechos. No obstante, desde su experiencia laboral, creen, en un $78,82 \%$, que las empresas no cumplen esta legislación.

Referente a los recursos tecnológicos y humanos necesarios para poder desarrollar plenamente el trabajo, consideran que sus empresas los proporcionan adecuadamente en un 57, I9 \% en el primer caso y en un $55,67 \%$ en el segundo.

El 96,67\% considera necesario que los servicios de empleo de las asociaciones de personas con discapacidad formen a los empleadores en el desarrollo de entornos laborales accesibles.

\subsubsection{Actitudes y creencias hacia la discapacidad por parte del entorno laboral}

La mayoría de los titulados $(62,48 \%)$ piensa que los empleadores creen que contratar a un titulado con discapacidad tendrá repercusiones económicas negativas. Desde su experiencia laboral, los titulados, en un $69,74 \%$, consideran que la gran mayoría de los compañeros de trabajo no hacen de la discapacidad una barrera para el desarrollo de la actividad profesional y, a su vez, opinan (7I,7 I \%) que tampoco hacen de la discapacidad una barrera para las relaciones sociales en el trabajo.

Los titulados con discapacidad, teniendo en cuenta su experiencia laboral, creen que los empresarios valoran el dominio de las competencias profesionales en el grado que indica para cada una de ellas el Gráfico 6 de la página siguiente. Vemos como este grupo de titulados opina que los empresarios valoran muy favorablemente todas las competencias profesionales. Las relacionamos siguiendo el grado de mayor a menor valoración: manejo del ordenador; capacidad de adaptarse a nuevas situaciones, flexibilidad; preocupación por la calidad; habilidades comunicativas; habilidad para trabajar de forma autónoma y tomar decisiones; capacidad de organizar y planificar; capacidad de trabajar bajo presión; motivación, entusiasmo y ganas de aprender; habilidades interpersonales; habilidades de búsqueda y gestión de información; iniciativa y espíritu emprendedor; capacidad de negociación, saber convencer y aceptar otros puntos de vista; capacidad para generar nuevas ideas, creatividad e innovación; dominio de la lengua inglesa; potencial de liderazgo.

\subsubsection{Promoción y satisfacción laboral}

El grado de satisfacción expresado por los titulados en relación a su experiencia laboral es muy alto en un $30,26 \%$, alto en un $27,53 \%$, medio en un 25 , I I \% y bajo o muy bajo en un I7,OI \%.

Además los titulados con discapacidad manifiestan su deseo de promocionar laboralmente en un 88,20\%. El 67,78\% opina que las empresas les han proporcionado las mismas opciones de promoción que a sus compañeros. También manifiestan, en un $6 \mathrm{I}, 57 \%$, no tener dificultades para actualizar su formación profesional.

\subsection{Percepción de las empresas acerca de la inserción laboral de los titulados universitarios con discapacidad}

Dada la escasa participación por parte de las empresas, un total de 16 sobre 580 , los resultados que se presentan son comentados de modo general debido a la poca representatividad. En ningún caso podrán ser extrapolables ni generalizables. No obstante, por tratarse de uno de los objetivos planteados 
Gráfico 6. Opinión de los titulados universitarios con discapacidad respecto a la valoración de los empleadores sobre las competencias profesionales (2010). Porcentajes

Habilidades comunicativas

Dominio de la lengua inglesa

Habilidad para trabajar de forma autónoma y tomar decisiones

Iniciativa y espíritu emprendedor

Preocupación por la calidad, por hacer bien las cosas

Motivación, entusiasmo y ganas de aprender

Capacidad de organizar y planificar, saber administrar el tiempo

Capacidad de trabajar bajo presión

Potencial de liderazgo, capacidad de influir y motivar en otros

Capacidad de negociación, saber convencer y aceptar otros puntos de vista

Habilidades interpersonales, saber relacionarse con otros

Capacidad para adaptarse a nuevas situaciones, flexibilidad

Capacidad para generar nuevas ideas, creatividad e innovación

Manejo del ordenador

Habilidades de búsqueda y gestión de información
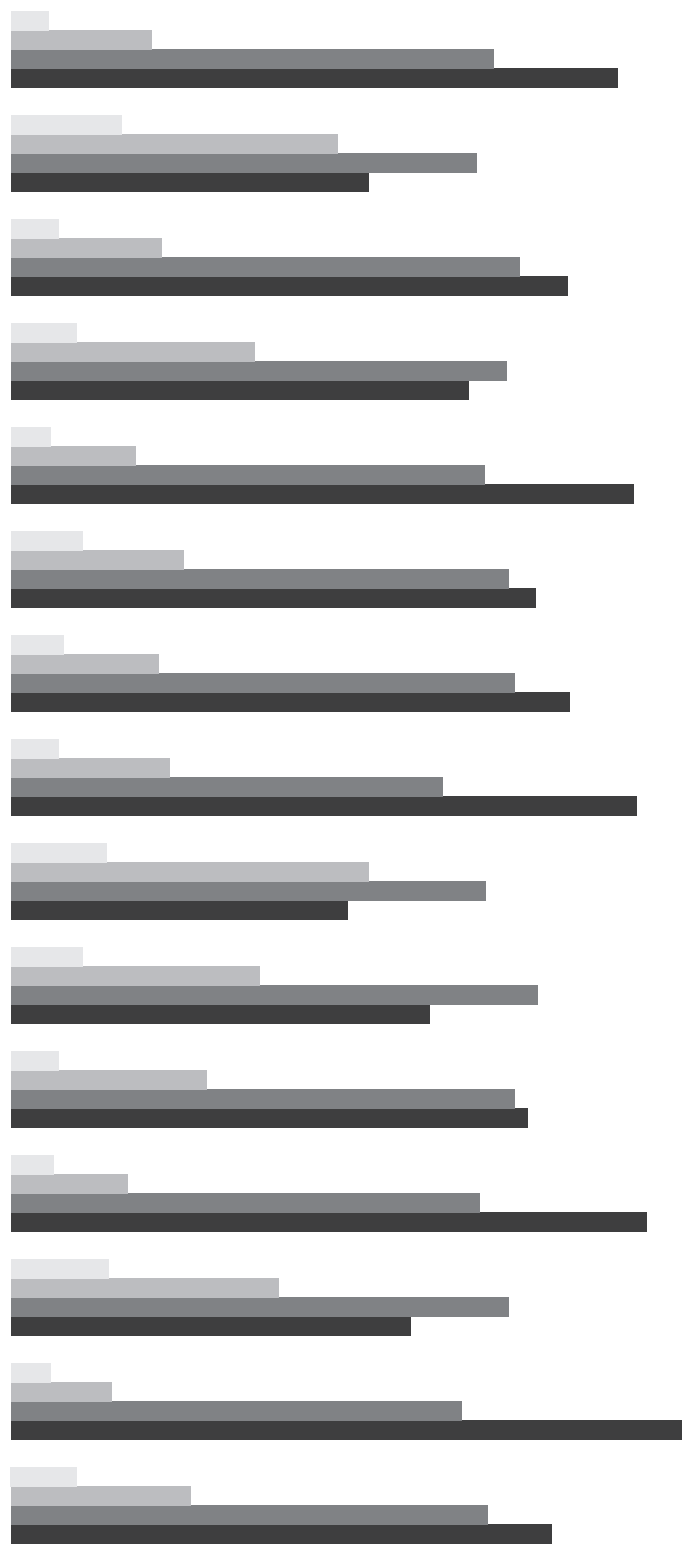

10

20

30

40

50
Nada
-1. Poco
Bastante
aucho

Fuente: Elaboración propia. 
en esta investigación hemos creído oportuno presentar los resultados bajo la cautela que ya hemos comentado.

Las empresas valoran positivamente tener estudiantes con discapacidad en prácticas, siendo ésta una experiencia que favorece la contratación de titulados universitarios con discapacidad. Las empresas con experiencia consideran que es una buena manera de eliminar los prejuicios que se dan en el entorno laboral. Piensan que las prácticas facilitan la sensibilización y el conocimiento que hará posible la adaptación del puesto de trabajo para el futuro empleado con discapacidad.

Referente a los factores que facilitan la contratación de titulados universitarios con discapacidad, según las empresas participantes con experiencia, consideran por igual nivel de importancia: la colaboración con fundaciones que ofrezcan servicios de inserción laboral específicos, con el objetivo de ayudar a identificar los perfiles adecuados a los puestos de trabajo; la responsabilidad social corporativa que impregna la política global de la empresa; y el cumplimiento de la legislación sobre el empleo de personas con discapacidad.

Las empresas participantes sin experiencia, opinan que el factor facilitador más significativo sería desarrollar una política de subvenciones más eficaz.

Las empresas con experiencia también manifiestan que la principal barrera es la dificultad para identificar los perfiles de los titulados con discapacidad, adecuados a los puestos de trabajo.

Las empresas sin experiencia consideran como obstaculizador la escasa e inadecuada información existente para conocer las condiciones y el proceso de contratación de estos titulados.

Ambos tipos de empresas creen que contratar a un titulado con discapacidad no tendrá repercusiones económicas negativas. Afirman percibir a los titulados con discapacidad como personas competentes para desarrollar un puesto de trabajo y con capacidad para trabajar en equipo. Respecto a los compañeros, creen que éstos no hacen de la discapacidad una barrera para el desarrollo de la actividad profesional compartida, como tampoco hacen de la discapacidad una barrera para las relaciones sociales en el trabajo.

Ambos tipos de empresa afirman que perciben a los titulados con discapacidad como personas competentes para desarrollar un puesto de trabajo y con capacidad para el trabajo en equipo.

Las empresas con experiencia expresan, en su mayoría, un grado de satisfacción alto como empleador. Estas empresas ven la incorporación de estos titulados como una aportación muy positiva porque normaliza la diversidad en su empresa, aporta distintos puntos de vista y planteamientos desde otra perspectiva. Las empresas sin experiencia opinan que estos titulados pueden aportar lo mismo que cualquier otro trabajador. Especifican el valor añadido que puede representar tener un empleado con discapacidad a través de los siguientes aspectos: capacidad humana, diversidad, función y responsabilidad social y una nueva visión para la empresa.

\section{Conclusiones}

En cuanto al primer objetivo de nuestra investigación, conocer la experiencia de los titulados universitarios españoles con discapacidad, en relación a su formación para acceder al mercado laboral ordinario, podemos concluir que la formación universitaria se revela como una vía importante para el acceso de las personas con discapacidad al mercado laboral ordinario. Por otra parte, también se constata que los titulados universitarios con discapacidad, generalmente, no reciben en la universidad los apoyos que serían suficientes para poder desarrollar todas las competencias profesionales. 
Además, se evidencia que las prácticas profesionales se muestran como una oportunidad para: conocer las propias capacidades en un entorno laboral ordinario; desarrollar el conocimiento mutuo entre los futuros profesionales universitarios con discapacidad y las empresas; y contribuir a la des-estigmatización de las futuras posibilidades laborales.

En relación al segundo objetivo, identificar los factores percibidos como obstáculos y los percibidos como facilitadores por parte de los titulados universitarios españoles con discapacidad, en el momento de su inserción al mercado laboral ordinario, se concluye que el principal factor obstaculizador es la percepción negativa de la discapacidad por parte de las empresas. Al mismo tiempo, se revela como principal factor facilitador el cumplimiento de la legislación sobre empleo, de las actuales medidas de acción positiva y la aplicación de las medidas sancionadoras, por parte de la administración y de las empresas.

Respecto al tercer objetivo, conocer la percepción de las empresas acerca de los titulados universitarios españoles con discapacidad, en el momento de su inserción al mercado laboral ordinario, consideramos importante manifestar que debido a la escasa participación del sector empresarial en este estudio no se ha podido obtener información significativa para conocer la percepción de las empresas. No obstante, y debido a la falta de estudios en nuestro país sobre este tema, queremos dejar constancia de que las empresas participantes han manifestado un alto grado de satisfacción en relación a su experiencia con empleados titulados universitarios con discapacidad. Por este motivo, concluimos que es imprescindible fomentar la participación del sector empresarial en otras investigaciones que aporten datos más representativos. Entendemos que poder obtener esta información es esencial para poder desarrollar propuestas que garanticen la plena inclusión al mercado laboral de los titulados universitarios con discapacidad.

En cuanto al cuarto objetivo, plantear propuestas de mejora para favorecer la inclusión al mercado laboral de los titulados universitarios españoles con discapacidad, planteamos un conjunto de propuestas dirigidas en primer lugar a mejorar la formación de los estudiantes universitarios con discapacidad y en segundo lugar a mejorar su proceso de inserción laboral al mercado ordinario.

Referente a estas propuestas de mejora para la formación universitaria de los estudiantes con discapacidad proponemos que:

- Las universidades deberían asegurar que los apoyos ofrecidos respondan a las necesidades de todos los estudiantes, incluidos los que presentan algún tipo de discapacidad, para desarrollar plenamente todas las competencias profesionalizadoras. Y, sobre todo, en aquellas que los titulados universitarios con discapacidad expresan haber recibido menor apoyo (el domino de la lengua inglesa, el potencial de liderazgo, la capacidad de negociación y la capacidad de generar nuevas ideas). Además de ofrecer estos apoyos, se debería potenciar metodologías inclusivas que permitieran dar respuesta a toda la diversidad de estudiantes presentes en las aulas universitarias de acorde con el modelo de educación inclusiva. Todo esto revertiría en la calidad de la formación de todos los titulados universitarios.

- También se debería fomentar un modelo de prácticas, por parte de la universidad y de la empresa, que contribuyera a generar una retroalimentación positiva para desarrollar una relación de cooperación entre los estudiantes y la empresa que permitiera el progreso mutuo y derivase a crear contextos laborales normalizados.

En cuanto a las propuestas dirigidas a mejorar el proceso de inserción al mercado laboral ordinario de los titulados universitarios con discapacidad planteamos que:

- Para mejorar y normalizar este proceso entendemos que se debería gestionar a través de las bolsas generales de empleo, no 
específicas para personas con discapacidad. Esto no insta la necesidad de hacer constar el tipo y grado de discapacidad para facilitar los apoyos adecuados si fueran necesarios. Por lo tanto, consideramos que la administración, las fundaciones y asociaciones de personas con discapacidad deberían dirigir sus esfuerzos a asesorar y orientar a las empresas y a los candidatos con el fin de que puedan conseguir mutuamente un proceso de adaptación exitoso en un entorno laboral ordinario.

- Además creemos necesario que la administración, las fundaciones y asociaciones de personas con discapacidad lleven a cabo políticas de sensibilización y de educación orientadas a la sociedad en general, con el fin de hacer visibles las capacidades reales de los titulados universitarios con discapacidad en la vida cotidiana y, de manera muy especial, en el trabajo desarrollado en entornos ordinarios. La repercusión de estas políticas permitiría, especialmente, a las empresas reconocer las posibilidades profesionales de los titulados universitarios con discapacidad y se evitaría la oferta de puestos de trabajo inferiores a su nivel de formación. Puesto que queda demostrado, según la experiencia de estos titulados, que es posible un desarrollo y promoción profesional pleno y satisfactorio.

- Finalmente, sería necesario potenciar modelos educativos que permitieran, a lo largo de la vida, el reconocimiento de la propia identidad de la persona con discapacidad para poder identificar sus competencias y habilidades y así afrontar con seguridad y realidad los retos propios de cada momento del ciclo vital. Uno de estos retos es la inserción laboral. Consideramos que este autoconocimiento favorecería a los titulados universitarios con discapacidad una mayor seguridad en los procesos de selección y de promoción profesional normalizados. De esta manera, los candidatos no concebirían la discapacidad como una barrera para su inserción laboral. 


\section{Referencias bibliográficas}

Buendía, L. et al. (Eds.) (I997): Métodos de Investigación en Psicopedagogía. Madrid: Ed. McGraw-Hill.

Campoy, T.J. y Pantoja, A. (2003): “Transición al mundo laboral de alumnos universitarios con discapacidades físicas y sensoriales". Revista de educación Especial, 33: 36-39.

Coleman Williams, B. (2008): Transition from college to work: Lived employment experiences and perceptions of college seniors and recent college graduates with physical disabilities seeking employment opportunities (Unpublished).

Dalmau Montalà, M. et al. (20I0): Integración laboral de los universitarios españoles con discapacidad. Detección de las fortalezas $y$ debilidades en el momento del acceso al mercado laboral español. Percepción de los universitarios y percepción de las empresas. Madrid: Fundación Universia.

David, B. y Butler, V.L. (2002): "Estudio comparativo de políticas laborales que contribuyen a evitar la discriminación de personas con discapacidad". Psicología de la Rehabilitación, 49 (I): 28.

España. Real Decreto-Ley Io/20io, de I 6 de junio, de medidas urgentes para la reforma del mercado de trabajo. Boletín Oficial del Estado, núm. I 47 de I7 de junio de 20IO, p. 5166251699.

España. Real Decreto I 720/2007, de 2 I de diciembre, por el que se aprueba el Reglamento de desarrollo de la Ley Orgánica I 5/I999, de I 3 de diciembre, de protección de datos de carácter personal. Boletín Oficial del Estado, núm. I7 de I9 de enero de 2008, p. 4IO3-4I36.

España. Ley 43/2006, de 29 de diciembre de 2006 para la mejora del crecimiento y el empleo. Boletín Oficial del Estado, núm. 3 I2, de 30 de diciembre de 2006, p. 46586-46600.

España. Orden PRE I 822/2006, de 9 de junio, por la que se establecen criterios generales para la adaptación de tiempos adicionales en los procesos de selección para el acceso al empleo de las personas con discapacidad. Boletín Oficial del Estado, núm. I 40 de 13 de junio de 2006, p. $22530-22533$.

España. Orden TAS/736/2005, de I7 de marzo, por la que se regula la estructura y funcionamiento de la Oficina Permanente Especializada del Consejo Nacional de la Discapacidad. Boletín Oficial del Estado, núm. 73 de 26 de marzo de 2005 , p. I0445-10446.

España. Real Decreto, 227I/2004, de 3 de diciembre, por el que se regula el acceso al empleo público y la provisión de puestos de trabajo de las personas con discapacidad. Boletín Oficial del Estado, núm. 303 de I 7 de diciembre de 2004, p. 4I 26I-4I 264.

España. Real Decreto 290/2004, de 20 de febrero, por el que se regula los enclaves laborales como medida de fomento del empleo de las personas con discapacidad. Boletín Oficial del Estado, núm. 45 de 2 I de febrero de 2004 , p. 8386 839 I.

España. Ley 62/2003, de 30 de diciembre, de medidas fiscales, administrativas y del orden social. Boletín Oficial del Estado, núm. 3 I3, de 3I de diciembre de 2003, p. 46874-46992.

España. Ley 53/2003, de Io de diciembre, sobre empleo público de discapacitados. Boletín Oficial del Estado, núm. 296, de i I de diciembre de 2003, p. 44082-44083.

España. Ley $5 \mathrm{I} / 2003$, de 2 de diciembre, de igualdad de oportunidades, no discriminación y accesibilidad universal de las personas con discapacidad. Boletín Oficial del Estado, núm. 289 , de 3 de diciembre de 2003 , p. 43 I 87 43195 .

España. Real Decreto 27/2000, de I4 de enero, por el que se establecen medidas alternativas de carácter excepcional al cumplimiento de la cuota de reserva del 2 por Ioo en favor de trabajadores discapacitados en empresas de 50 o más trabajadores. Boletín Oficial del Estado, núm. 22 de 26 de enero de 2000, p. 34IO-34I 2. 
España. Ley I3/I982, de 7 de abril, de integración social de los minusválidos. Boletín Oficial del Estado, núm. I95, de 16 de agosto de I982, p.22054-22060.

España. Constitución Española, de 27 de diciembre de I978. Boletín Oficial del Estado, núm. 3 I I, de 29 de diciembre de I978, p. 29313-29424.

Hazer, J.T. y Bedell, K.V. (2000): "Effects of seeking accommodation and disability on preemployment evaluations". Journal of Applied Social Psychology, 30 (6): I 2OI-I 233.

Hernández, B. et al. (2008): "Reflections from employers on the disabled workforce: Focus groups with healthcare, hospitality and retail administrators”. Employ Responds Rights, 20: I 57-I 64 .

Hernández, B. y Keys, C. (2000): “Employer attitudes toward workers with and their ADA employment rights: A literature review". The Journal of Rehabilitation, 66 (4): 4-I6.

Johnson, A.L. (2006): "Students with disabilities in postsecondary education: Barriers to success and implications for professionals". Counseling Outfitters (en línea). <http:// counselingoutfitters.com/Johnson.htm>, acceso el 20-02-20IO.

Johnson, D.R. et al. (2002): "Current challenges facing secondary education and transition services". Exceptional Children, 68 (4): 51953 I.

Ministerio de Educación, Política Social y Deporte (Ed.) (2008): Estrategia global de acción para el empleo de personas con discapacidad 2008-20I2. Madrid: Ministerio de Educación, Política Social y Deportes.

Osgood, W. et al. (2005): The transition to adulthood for vulnerable populations (en línea). <http://agexted.cas.psu.edu/faculty/Docs/ WhyFocusTransition.pdf>, acceso el 20-02-20IO.

Pearson, V. et al. (2003): “To tell or not to tell: Disability disclosure and job application outcomes". Journal of Rehabilitation, 69 (4): $35-38$.

Polo, M. T. (2006): "Barreras físicas y psicosociales en el proceso de inserción laboral de los universitarios discapacitados visuales". En Cifuentes García, M.A. et al:: La Accesibilidad como medio para educar en la diversidad. Educación, diversidad y accesibilidad en el entorno Europeo. Burgos: Universidad de Burgos: 365-370.

Posthuma, R.A. et al. (2002): "Beyond employment interview validity: A comprehensive narrative review of recent research and trends over time”. Personnel Psychology, 55: I-8I.

Spirito, R. y Bellini, J. (2008): “Invisible disability disclosure in an employment interview: Impact on employers' hiring decisions and views of employability". Rehabilitation Counseling Bulletin, 52 (I): 6-I 5.

Thakker, D. y Solomon, P. (I999): “Factors influencing managers adherence to the Americans with disabilities act". Administration and Policy in Mental Health, $26(3): 2$ I3-2I9.

Unión Europea. Comunicación de la Comisión al Parlamento Europeo, al Consejo Económico y Social Europeo y al Comité de las Regiones. Estrategia Europea sobre Discapacidad 20 Io2020: un compromiso renovado para una Europa sin barreras. SEC I323/I 324 (Comisión Europea. Bruselas I 5.I I.20IO 20I0).

Unión Europea. Directiva 2000/78/CE de Consejo, de 27 de noviembre de 2000 , relativa al establecimiento de un marco general para la igualdad de trato en el empleo y la ocupación. L3037I 6 (2000) (en línea). <http://www.cde. ua.es/cde/doce.htm>, acceso el O2-I2-2OI I

Unión Europea. Resolución del Consejo de la Unión Europea, de I7 de junio de I999, relativa a la igualdad de oportunidades laborales de las personas con minusvalía I999/C I 86/02(I999) (en línea). <http://www. cde.ua.es/cde/doce.htm>, acceso el 02-I2-2OI I

Universia, Accenture y Fundación Telefónica (2008): Las competencias profesionales en los estudiantes preuniversitarios. Madrid: ACCENTURE.

Valls, M. et al. (2004): "La inserción de las personas con discapacidad en el trabajo 
ordinario. El papel de la familia”. Revista de Educación, 334: 99-II7.

Vickers, M. (2008): "From the editor-in-chief's desk: Difference, diversity, and discrimination at work-revisiting stigma". Employee Responsibilities and Rights Journal: I 53-I 56.

Vila, M. y Pallisera, M. (2002): "La integración socio laboral de personas con discapacidad y formación superior". Revista Educación Especial, 33: 5 I-7 I.

Wagner, M. et al. (2007): "Perceptions and expectations of youth with disabilities. A special topic report of findings from the national longitudinal transition study-2 (NLTS2)". The Journal for Vocational Special Needs Education, 30 (I): I3-I7. 